\title{
Cervical spine involvement in rheumatoid arthritis over time: results from a meta-analysis
}

\author{
Tony Zhang and Janet Pope*
}

\begin{abstract}
Introduction: Complications in rheumatoid arthritis (RA) seem less common than they were years ago. The prevalence and progression of anterior atlantoaxial subluxations (aAASs), vertical subluxations (VSs), subaxial subluxations (SASs), and associated cervical myelopathy in RA over the past 50 years were determined.
\end{abstract}

Methods: A literature search was performed by using Medline-OVID/EMBASE, PubMed, and Scopus (from 1960 to June 21, 2014). Prevalence studies were included if the sample size was at least 100 or the prevalence/progression of cervical subluxations was reported. Study quality was assessed by using the Strengthening the Reporting of Observational Studies in Epidemiology (STROBE) checklist. Prevalence of cervical subluxations was calculated for each study. Student's $t$ test and meta-regression were used to evaluate for significance.

Results: In total, 12,249 citations were identified and 59 studies were included. The prevalence of aAAS decreased from 36\% (95\% confidence interval (Cl) 30\% to 42\%) before the 1980s to $24 \%$ (95\% Cl 13\% to 36\%) in the 2000s $(P=0.04)$. The overall prevalence rates were $11 \%$ (95\% Cl 10\% to 19\%) for VS, $13 \%$ (95\% Cl 12\% to 20\%) for SAS, and $5 \%$ (95\% Cl 3\% to 9\%) for cervical myelopathy, and there were no significant temporal changes. Rates of progression of aAAS, VS, and SAS were 4, 6, and 3 lesions per 100 patients per year, respectively. The incidence of new or progressive cervical myelopathy was 2 cases per 100 patients with known cervical subluxations per year.

Conclusions: Since the 1960s, only aAAS has decreased dramatically. It is still more than twice as common as VS or SAS. No temporal changes in the development of cervical myelopathy in affected patients with RA were noted. The progression rates of cervical subluxations and myelopathy were unchanged over time.

\section{Introduction}

Rheumatoid arthritis (RA) is a chronic systemic inflammatory disease that primarily affects the joints. Although inflammatory arthritis of the small joints in the hands and feet is a common clinical manifestation, the cervical spine can also be affected. In fact, cases surfaced as early as 1890 , when A. E. Garrod reported 178 patients with cervical spine involvement in a series of 500 patients with RA [1]. Cervical spine involvement can take many forms. Reported findings include vertebral endplate erosions, spinous process erosions, and apophyseal joint changes, such as osteoporosis, blurring, and fusion $[2,3]$. The most characteristic lesions are subluxations $[4,5]$.

The atlas-axis-cervical vertebrae 1 and 2 (C1 and $\mathrm{C} 2$ )-articulation is one of the prime disease targets. The

\footnotetext{
* Correspondence: janet.pope@sjhc.london.on.ca

Schulich School of Medicine \& Dentistry, Western University of Canada

(formerly University of Western Ontario), St. Joseph Health Care, 268
} Grosvenor Street, London, ON N6A 4 V2, Canada erosive pannus formation at this joint often leads to bony destruction and laxity in the surrounding ligamentous complex, especially the transverse ligament that aligns that atlas and axis. The subsequent loss of anchoring structures results in atlantoaxial subluxation (AAS) [6]. The subluxation can be anterior, posterior, lateral, and rotatory. The anterior atlantoaxial subluxation (aAAS) is the most common subtype; the reported prevalence ranges from $10 \%$ to $55 \%[2,3,7-9]$. This wide range may be related to the variation in the radiographic definition of aAAS. Separation of the anterior odontoid peg (dens) from the anterior ring of atlas (altanto-dental interval) of greater than $2.5 \mathrm{~mm}$ to 5 $\mathrm{mm}$ has been considered pathological [2,10-12]. Posterior AASs are less frequent and often due to fracture of the dens [13]. Lateral subluxations are considered when lateral masses of $\mathrm{C} 1$ are displaced laterally more than $2 \mathrm{~mm}$ in comparison with $\mathrm{C} 2$. They can lead to head tilt and rotational deformities [5].

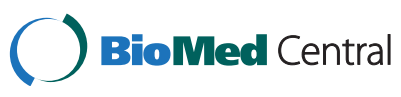

(c) 2015 Zhang and Pope; licensee BioMed Central. This is an Open Access article distributed under the terms of the Creative Commons Attribution License (http://creativecommons.org/licenses/by/4.0), which permits unrestricted use, distribution, and reproduction in any medium, provided the original work is properly cited. The Creative Commons Public Domain Dedication waiver (http://creativecommons.org/publicdomain/zero/1.0/) applies to the data made available in this article, unless otherwise stated. 
Another form of subluxation is the vertical subluxation of the axis (VS), also known as altantoaxial impaction, cranial settling, superior migration of the odontoid, or psuedobasilar invagination. It is secondary to the destruction of occipitoatlantal and atlantoaxial joints and surrounding soft tissues [5]. Not surprisingly, many studies have shown that AAS and the destruction of $\mathrm{C} 1-\mathrm{C} 2$ articulation tend to predate the development of VS [14-16].

Lastly, subaxial subluxation (SAS) is associated with the damage to the facet joints, interspinous ligaments, and intervertebral discs. It can happen at one or multiple levels, leading to a step-ladder deformity and kyphosis [5]. SAS is defined by a misalignment of more than 3 $\mathrm{mm}$ between the anterior bodies of two consecutive vertebrae, although a threshold of $1 \mathrm{~mm}$ has also been found in studies $[4,17]$. Neck subluxations can develop over the course of the disease process, and there is an increased risk of developing neurological complications. Tinnitus, vertigo, and visual changes associated with vertebrobasilar insufficiency or brainstem compression can arise [6]. Patients may experience myelopathic symptoms. Once severe neurological complications develop, the prognosis can be grave; 1-year mortality can be as high as $50 \%$ if the condition is left untreated [18].

It appears that RA complications such as rheumatoid nodules, corneal melts, vasculitis, and C-spine subluxations are less frequent than they were years ago. Given the improved RA management over the past 50 years, our objectives were to quantify and evaluate temporal changes in the prevalence and progression of various RA-related cervical subluxations and cervical myelopathy.

\section{Methods}

\section{Study selection}

A comprehensive literature search was performed by using the Medline-OVID/EMBASE, PubMed, and Scopus databases from 1960 to June 21, 2014. We looked for studies of cervical subluxations in patients with RA by using the following search strategy:

1. rheumatoid arthritis

2. cervical vertebrae

3. atlanto-axial joint

4. spinal diseases

5. joint instability

6. AAS

7. atlantoaxial instability

8. atlantoaxial dislocation

9. VS

10. superior migration of the odontoid

11. cranial settling

12. pseudobasilar invagination

13. atlantoaxial impaction

14. SAS 15.or/2 to 14

16.1 and 15 .

Identified titles/abstracts were reviewed, and full reports were obtained if appropriate. Studies were considered if they provided data on the prevalence or progression of any cervical subluxations in patients with RA. Studies reporting prevalence required a sample size of at least 100 patients with RA. Another inclusion criterion was publication in English. Case reports, case series of fewer than 100 patients for the estimate of prevalence, and review articles were excluded. Cervical spine involvement of RA patients who were followed over time was included for the rate of progression analyses. Additional articles were retrieved by hand by searching relevant references.

\section{Data collection}

Information from the studies was extracted by one reviewer (TZ) and ambiguities were resolved with the other reviewer (JP). A standard data extraction form was used to extract the following information:

Prevalence studies: year of publication, author, location of study, study design, patient population, sample size, number of females, mean age, mean disease duration, and proportion with any cervical changes, aAAS, posterior AAS, lateral AAS, rotatory AAS, VAS, SAS, cervical myelopathy, brainstem compression/vertebral artery involvement, and their respective definitions.

Progression studies: year of publication, author, location of study, study design, patient population, sample size, number of females, mean age, mean disease duration, years of follow-up, baseline, and rate of progression of aAAS, VS, SAS, cervical myelopathy and number of progressive/new cervical myelopathies. If studies included patients with RA and other rheumatic diseases, only data pertaining to the RA cohort were extracted.

\section{Quality assessment}

Each study was assessed by using the Strengthening the Reporting of Observational Studies in Epidemiology (STROBE) checklist [19], which is a 22-item checklist relating to the title and abstract of the article (item 1), background and objectives (items 2 and 3), methods (items 4 to 12 ), results (items 13 to 17 ), discussion (items 18 to 21 ), and funding (item 22). The purpose of STROBE is not to give a quality score but to ensure clear presentation of reporting.

\section{Statistical analysis}

Proportions were pooled with a random effects model [20]. Forest plots were created to estimate prevalence with a $95 \%$ confidence interval (CI). The $\mathrm{I}^{2}$ statistic was used to quantify the magnitude of heterogeneity (mild, $0 \%$ to $30 \%$; moderate, $31 \%$ to $50 \%$; high, more than 
$50 \%)$. Tau-squared was the square root of the betweenstudy variance, and $P$ value was for Cochrane's $Q$, the classic measure of heterogeneity. Owing to significant heterogeneity, Forest plots and pooled estimates were not reported. Student's $t$ test was performed to evaluate regional differences in aAAS. Meta-regression through a random effects model was also used to explore the study-level associations between the prevalence of various $\mathrm{C}$-spine complications and year of publication. A $P$ value of less than 0.05 was considered statistically significant. Publication bias was determined by using funnel plots.

\section{Results}

\section{Search results}

The literature search identified 12,249 citations with 412 duplicates. Titles or abstracts (if available) were screened for eligibility, yielding 126 citations for full text review. Twelve studies were case reports. Twenty-nine studies were editorials or reviews. Eleven studies did not report on the rate or progression of cervical complications. Eleven studies examined patients with severe neck complaints or suspected/known cervical instabilities. Six excluded studies examined the prevalence of cervical instabilities in RA but had a sample size of less than 100 . Two articles were identified by hand-searching key references. In total, 67 articles were excluded, leaving 59 studies to be included in our meta-analysis (Figure 1).

\section{Description of the included studies and participants}

Fifty studies reported on the prevalence of cervical instabilities. Three studies were published in the 1960s with 533 participants (4\% of pooled study population), nine studies in the 1970 s with 2,798 participants (23\%), nine studies in the 1980 s with 1,449 participants (12\%), nine studies in the 1990s with 1,653 participants (14\%), 13 studies in the 2000s with 3,777 participants (31\%), and seven studies in the 2010s with 2,012 participants (16\%) [2-4,7-12,15,17,21-59]. The total number of enrolled patients was 12,222. Major world regions were represented. Six studies were from the United States, including 855 participants (7\% of pooled study population) $[3,15,17,21,33,35]$. Twenty-six studies were from Europe with a total of 7,315 participants (60\%) $[2,4,7,10,22-25,27-31,34,37,38,40,43-46,49-52,59]$. Sixteen studies were conducted in Asia, totaling 3,662 participants (30\%) [8,9,12,26,32,39,41,42,47,48,53-58]. An additional study compared a Malaysian cohort with a British cohort with a total of 140 patients [36]. One study was from Africa and included 250 people (2\%) [11]. The average female representation was $75 \%$. The mean age at the time of outcome assessment was 58 years old (range of 33 to 69 years), and the mean disease duration was 12 years (range of 2 to 30 years).
Twenty studies were included for analyzing the progression of cervical instabilities. Data were obtained from 12 of the studies described above as well as nine additional studies $[7,8,14-16,22,23,25,29,32,42,55,56,60-66]$. The number of enrolled participants was 2,157, and the average followup was 6 years (range of 3 to 10 years). Eighty percent of the participants were female. The mean age and disease duration at the time of final assessment were 60 years (range of 50 to 67 years) and 15 years (range of 7 to 30 years), respectively.

Across all studies, the median number of items fulfilled on the STROBE checklist was 16 (range of 11 to 19) and reporting was improved in more recent studies. Characteristics of the included studies are shown in Tables 1 and 2 .

\section{Prevalence of any rheumatoid arthritis-related changes, cervical subluxations, and cervical myelopathy}

Twelve studies reported the prevalence of any RA-related cervical changes, not limited to subluxations. Out of 3,559 patients, 1,597 (45\%) were found to have one or more of those radiographic changes. There were no significant changes over time of publication $(P=0.71)$.

AAS was the most common subluxation found in our study. Twenty-seven percent (2,737 patients) had aAAS. Lateral AAS was reported in 68 patients $(0.7 \%)$. Posterior and rotatory AASs were found in $21(0.2 \%)$ and 10 (0.1\%), respectively. In comparisons among different world regions, the prevalences of aAAS were $25 \%, 27 \%$, and $31 \%$ for Europe, North America, and Asia, respectively $(P=0.13)$. The prevalences of aAAS were $36 \%$ in the 1970 s and earlier (95\% CI 30\% to $42 \%$ ), $36 \%$ in the 1980 s (95\% CI $23 \%$ to $42 \%$ ), $32 \%$ in the 1990 s (95\% CI $20 \%$ to $44 \%$ ), and $24 \%$ in the 2000 s (95\% CI $13 \%$ to $36 \%$ ) $(P=0.04)$. VS and SAS had comparable prevalence rates. VSs were reported in 831 of 7,675 patients with RA with a prevalence of $11 \%$ (95\% CI $10 \%$ to $19 \%$ ); SAS occurred in 838 of 6,672 patients with RA (13\%; $95 \%$ CI $12 \%$ to $20 \%)$. No significant temporal changes were noted for either VS or SAS $(P=0.17$ and $P=0.49$, respectively).

Twenty-three studies with 5,106 patients with RA reported on cervical myelopathy. Two hundred seventy-one patients (prevalence of 5\%) had observed neurological deficits corresponding to Ranawat Cervical Myelopathy Classification II and above (95\% CI 3\% to 9\%) [67]. We did not observe a significant change over time $(P=0.22)$. In terms of serious neurological complications, nine patients $(0.2 \%)$ were observed to develop paraplegia. Ten additional patients $(0.2 \%)$ had symptoms of possible brainstem involvement, including nausea, vertigo, or drop attacks.

Progression of cervical subluxations and cervical myelopathy Sixteen studies reported on the progression of 945 aAAS lesions. After 10,046 person-years, 219 of the existing 


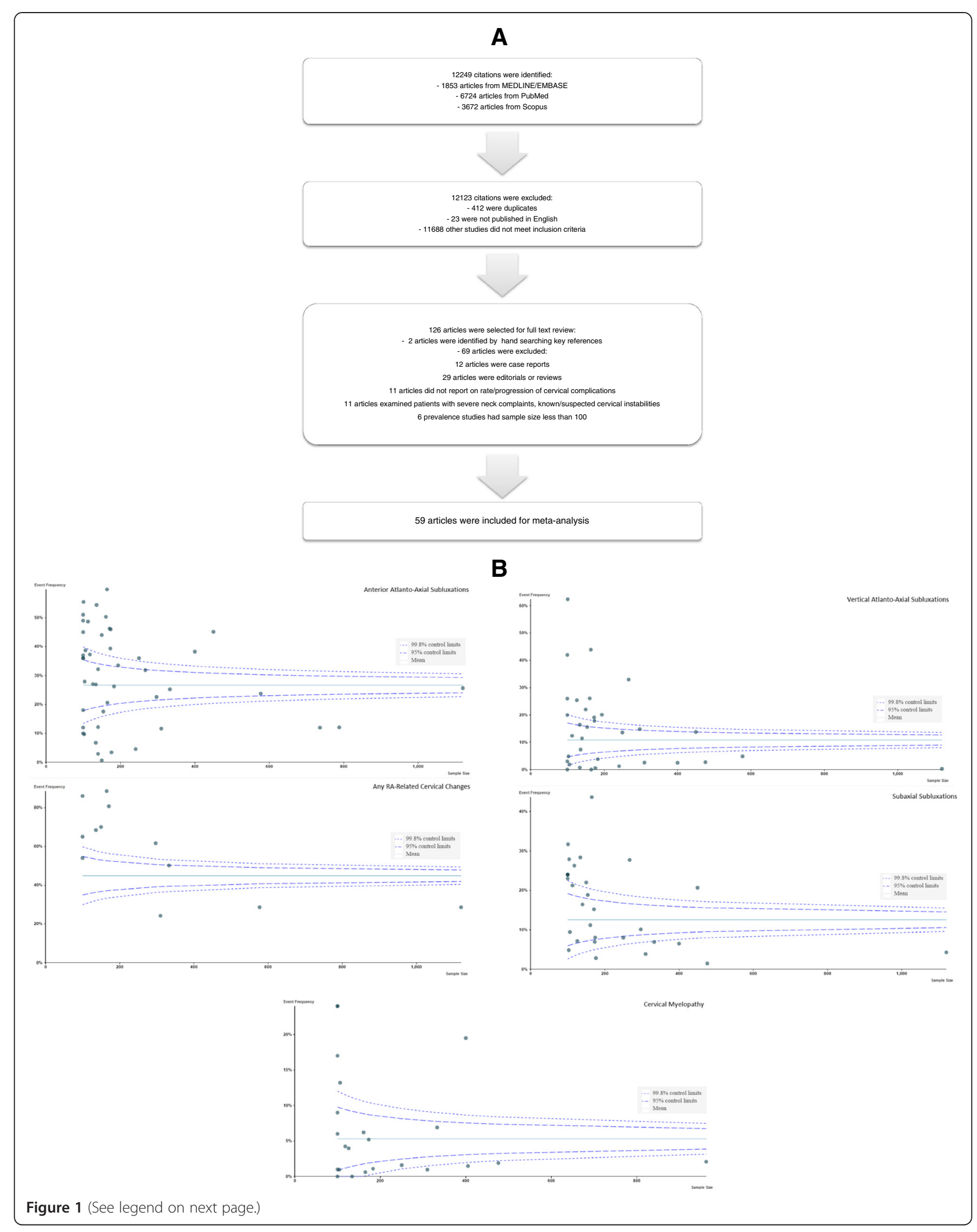


(See figure on previous page.)

Figure 1 (A) Search strategy for articles and (B) Funnel plots to determine if there was publication bias. Funnel plot 1: Graph of sample size of individual study (x-axis) and its respective prevalence of anterior atlanto-axial subluxations (y-axis). Funnel plot 2: Graph of sample size of individual study ( $x$-axis) and its respective prevalence of rheumatoid arthritis (RA)-related cervical changes (y-axis). Funnel plot 3: Graph of sample size of individual study ( $x$-axis) and its respective prevalence of vertical atlanto-axial subluxations (y-axis). Funnel plot 4: Graph of sample size of individual study ( $\mathrm{x}$-axis) and its respective prevalence of subaxial subluxations (y-axis). Funnel plot 5: Graph of sample size of individual study (x-axis) and its respective prevalence of cervical myelopathy (y-axis).

subluxations had an increase in altanto-dental interval on radiography. Therefore, on average, 4 out of 100 existing aAAS lesions progressed per year. As for VS, 148 of 407 known lesions had radiographic progression, following 8,468 person-years. This corresponded to a progression rate of 6 per 100 lesions per year. Lastly, only 5 studies reported on SAS progression. A total of 46 out of 208 existing lesions progressed during the 4,781 person-years of follow-up. Therefore, the rate of SAS progression was 3 lesions per 100 existing lesions per year. The rate of progression for these subluxations was not found to be significantly different over time (aAAS, $P=0.99$; VS, $P=0.49$ ). Owing to the small number of studies, the rate of SAS progression over time was not analyzed.

Cervical myelopathy was assessed in 1,310 patients with RA with 9,131 person-years of follow-up. A total of 772 people had AAS, VS, SAS, or a combination of subluxations. Seventy-nine had new or progressive cervical myelopathy at the end of follow-up. We thus calculated a rate of 1.5 new/progressive cervical myelopathies per 100 patients with known cervical subluxations per year. Over time, the rates were $0.8,2.1,1.3$, and 2.4 for the 1970 s, 1980s, 1990s, and 2000s, respectively $(P=0.05)$.

\section{Discussion}

Cervical spine involvement in RA has long been recognized. Varying degrees of prevalence have been reported as reflected in our literature search. This can be explained by numerous factors, such as differences in sample size, disease duration, follow-up period, medications used, and radiological criteria. There may also be reporting bias in which once something is well described, fewer publications follow over time. To the best of our knowledge, this is the first study to systematically evaluate the prevalence and progression of cervical subluxations and cervical myelopathy in patients with RA.

The earliest form of cervical instability in patients with RA has been shown to be a reducible AAS [62]. AAS is the most common cervical subluxation in RA. (AAS is twice as common as VS or SAS, and other types are very uncommon.) No regional differences in aAAS were found between Asia, Europe, and North America. However, a significant temporal reduction in the prevalence of aAAS exists, decreasing by one third from the 1960s and 1970s to 2000. The could reflect the changes in RA management (earlier introduction of DMARDs with higher doses and more combinations), or changing epidemiology of RA with fewer complications compared to years ago, and or reporting bias where the complications that are well described are less likely to be published over time so the contemporary rates may not be fully reported (publication bias).

The effects of DMARDs were addressed specifically in a number of studies. For example, Neva and colleagues recruited 198 early RA patients who were randomly assigned to either combination DMARDs (sulfasalazine, methotrexate, and hydroxychloroquine) or a single DMARD with or without prednisone [43]. After 2 years of follow-up, aAAS was found in $3 \%$ of the patients. None of the patients who were receiving combination therapies had aAAS. Lending further support to the role of DMARDs in preventing cervical involvement, biological agents were examined in two studies. A cohort of 38 early RA patients who received more than 2 years of continuous infliximab treatment in addition to methotrexate and prednisone was followed for 4 years [64]. Only one of the patients developed de novo AAS. In another study, a group of 91 patients who were on infliximab, etanercept, or tocilizumab was followed for 4 years [65] and three developed AAS.

Whereas the prevalence of aAAS seemed to be on the decline with the introduction of DMARDs, that of SAS and VS did not. This could be related to the natural progression of cervical subluxations. Our results demonstrated that, once formed, 4 out of 100 aAAS lesions would have an increase in atlanto-dental interval per year. After a certain point, AAS can have the appearance of stabilization or even improvement in the atlanto-dental interval on $\mathrm{x}$-ray, signaling the beginning of VS. For example, Rana followed 41 AAS patients over a period of 10 years. Ten percent of the patients had less AAS secondary to new development of VS and upward translocation of odontoid process [16]. Smith and colleagues reported a similar phenomenon in $13 \%$ of their cases [23]. SAS generally develops at a later stage and is often seen after development of VS [68]. The lack of temporal reduction in the prevalence of VS and SAS may therefore be because DMARDs are less effective in preventing progression of existing lesions or due to a very low prevalence resulting in insufficient power to detect a change. When biologics were used, if there was C-spine subluxation, $79 \%$ to $80 \%$ progressed further $[64,65]$. We suspect that, eventually, the prevalence of VS and SAS will decrease as fewer de novo AASs are being formed. 
Table 1 Characteristics of $\mathbf{5 0}$ studies reporting prevalence of cervical subluxations

\begin{tabular}{|c|c|c|c|c|c|c|c|}
\hline $\begin{array}{l}\text { Year of } \\
\text { publication }\end{array}$ & $\begin{array}{l}\text { First author } \\
\text { (reference) }\end{array}$ & Country & $\begin{array}{l}\text { STROBE checklist } \\
\text { (total = 22) }\end{array}$ & Sample size & $\begin{array}{l}\text { Female, number } \\
\text { (percentage) }\end{array}$ & $\begin{array}{l}\text { Mean age, } \\
\text { years }\end{array}$ & $\begin{array}{l}\text { Disease duration, } \\
\text { years }\end{array}$ \\
\hline 1963 & Bland [21] & USA & 11 & 100 & $65(65 \%)$ & 56 & 14.4 \\
\hline 1966 & Conlon [2] & New Zealand & 14 & 333 & $230(69 \%)$ & 52.7 & N/A \\
\hline 1969 & Park [3] & USA & 12 & 100 & N/A & N/A & 10 \\
\hline 1971 & Meikle [4] & Scotland & 15 & 118 & $83(70 \%)$ & 57.6 & 12.9 \\
\hline 1971 & Isdale [22] & New Zealand & 13 & 171 & N/A & N/A & 12.1 \\
\hline 1971 & Stevens [10] & UK & 16 & 100 & 73 (73\%) & 54.2 & 11.3 \\
\hline 1972 & Smith [23] & UK & 13 & 962 & $588(61 \%)$ & 51.3 & 7.4 \\
\hline 1975 & Henderson [24] & UK & 15 & 476 & N/A & N/A & N/A \\
\hline 1976 & Shaw [25] & UK & 11 & 100 & 73 (73\%) & 54.2 & N/A \\
\hline 1978 & Higashiyama [26] & Japan & 12 & 100 & 91 (91\%) & N/A & N/A \\
\hline 1978 & Chevrot [27] & France & 14 & 577 & N/A & N/A & N/A \\
\hline 1979 & Jensen [28] & Denmark & 14 & 194 & N/A & N/A & N/A \\
\hline 1981 & Winfield [29] & UK & 14 & 100 & $56(56 \%)$ & 54.8 & 7.7 \\
\hline 1981 & Pellici [15] & USA & 14 & 106 & 88 (83\%) & 62.6 & 30.1 \\
\hline 1982 & Halla [17] & USA & 15 & 126 & $86(68 \%)$ & 57.6 & $11.1 \mathrm{~s}$ \\
\hline 1983 & Winfield [7] & UK & 17 & 100 & $57(57 \%)$ & 57.1 & 10.0 \\
\hline 1984 & Haaland [30] & Norway & 16 & 104 & $77(74 \%)$ & N/A & 15.3 \\
\hline 1985 & Redlund-Johnell [31] & Sweden & 16 & 450 & $351(78 \%)$ & 63.5 & N/A \\
\hline 1987 & Morizono [32] & Japan & 14 & 100 & 92 (92\%) & 57.1 & 12.8 \\
\hline 1989 & Floyd [11] & South Africa & 15 & 250 & $187(75 \%)$ & 52.8 & N/A \\
\hline 1989 & Collins [33] & USA & 14 & 113 & $59(52 \%)$ & 55 & 15 \\
\hline 1990 & Kauppi [34] & Finland & 17 & 164 & $136(83 \%)$ & 57.3 & 19.3 \\
\hline 1990 & Halla [35] & USA & 16 & 310 & $198(64 \%)$ & 68.8 & 10.2 \\
\hline 1993 & Veerapen [36] & Malaysia Britain & 18 & 140 & $140(100 \%)$ & 46.5 & 10.1 \\
\hline 1994 & Stiskal [37] & Austria & 18 & 136 & $110(81 \%)$ & 57 & 13 \\
\hline 1994 & Montemerani [38] & Italy & 17 & 183 & 147 (80\%) & 33.4 & 12.3 \\
\hline 1996 & Aggarwal [39] & India & 16 & 100 & 73 (73\%) & N/A & 5 \\
\hline 1998 & Fujiwara [8] & Japan & 17 & 173 & $146(84 \%)$ & 55.6 & 12.5 \\
\hline 1998 & Schramm [40] & Germany & 14 & 150 & $134(89 \%)$ & 56.5 & 12.3 \\
\hline 1999 & Yoshida [41] & Japan & 16 & 297 & $251(85 \%)$ & 57.0 & 13.0 \\
\hline 2000 & Fujiwara [42] & Japan & 15 & 161 & $134(83 \%)$ & 59.5 & 16.5 \\
\hline 2000 & Neva [43] & Finland & 16 & 176 & $111(63 \%)$ & 48.5 & 2.5 \\
\hline 2001 & Riise [44] & Norway & 16 & 241 & $156(65 \%)$ & 61.9 & 5.4 \\
\hline 2003 & Carmona [45] & Spain & 18 & 788 & $562(71 \%)$ & 61.0 & 10.0 \\
\hline 2003 & Neva [46] & Finland & 17 & 103 & 70 (68\%) & 56.0 & 9.8 \\
\hline 2004 & Mitsuka [47] & Japan & 15 & 174 & 156 (90\%) & 60.9 & 19.1 \\
\hline 2004 & Pisitkun [48] & Thailand & 17 & 134 & 124 (93\%) & 48.9 & 5.0 \\
\hline 2004 & Naranjo [49] & Spain & 16 & 736 & $530(72 \%)$ & 61.4 & 9.0 \\
\hline 2005 & Zikou [50] & Greece & 17 & 165 & $143(87 \%)$ & 59.6 & 12.3 \\
\hline 2005 & Vesela [51] & Czech Republic & 15 & 400 & N/A & $N / A$ & N/A \\
\hline 2006 & Neva [52] & Finland & 18 & 154 & 117 (76\%) & 62.0 & 16.0 \\
\hline 2008 & Kim [53] & Korea & 18 & 405 & 365 (90\%) & 56.0 & 10.8 \\
\hline 2009 & Al-Ghamdi [54] & Saudi Arabia & 18 & 140 & $105(75 \%)$ & 47.2 & 6.9 \\
\hline
\end{tabular}


Table 1 Characteristics of $\mathbf{5 0}$ studies reporting prevalence of cervical subluxations (Continued)

\begin{tabular}{|c|c|c|c|c|c|c|c|}
\hline 2010 & Imagama [12] & Japan & 17 & 100 & 84 (84\%) & 61.0 & 13.0 \\
\hline 2010 & Ahn [55] & Korea & 16 & 1,120 & $\mathrm{~N} / \mathrm{A}$ & N/A & N/A \\
\hline 2011 & Yurube [56] & Japan & 18 & 267 & $220(82 \%)$ & 66.9 & N/A \\
\hline 2012 & Hirano [9] & Japan & 18 & 101 & N/A & 65.6 & 19.2 \\
\hline 2012 & Yurube [57] & Japan & 19 & 140 & 107 (76\%) & 68.3 & 18.5 \\
\hline 2012 & Eser [58] & Japan & 17 & 150 & $126(84 \%)$ & 53.2 & 12.3 \\
\hline 2013 & Blom [59] & The Netherlands & 16 & 134 & $90(67 \%)$ & 60.6 & 9.5 \\
\hline
\end{tabular}

N/A, not applicable; STROBE, Strengthening the Reporting of Observational Studies in Epidemiology.

Although cervical subluxations are common as illustrated above, their clinical presentation is often asymptomatic or associated with neck pain. Neurological complications are less frequent and tend to occur later in the disease course [69]. In our study, we reported a 5\% prevalence rate for observed neurological deficits in patients with RA on the basis of the Ranawat grading system. Class I patients have pain but no neural deficits and therefore were not counted for our study. Class II patients have subjective weakness with hyperreflexia and dyssthesias. Class III patients have objective weakness and long tract signs. Class IIIA patients are ambulatory whereas IIIB patients are non-ambulatory [67]. Serious complications were rare, however. Paraplegia was reported in $0.2 \%$ of patients with RA, and symptoms of possible brainstem involvement, such as vertigo and drop attacks, were found in another $0.2 \%$. We did not observe a decrease in the already-rare prevalence or progression of cervical myelopathy over time.

This study has limitations. Non-English studies were excluded. Although some asymmetries existed in our funnel plots, we do not believe that this represented major publication bias. Our data had significant heterogeneity. Age, disease duration, RA activity and severity, and treatments such as DMARDs and corticosteroids were not assessed. Estimates were generated at a population level. Inclusion criteria for some case series were not described in detail, and so the generalizability of the findings is unknown. We did not present the overall meta-analysis results, because heterogeneity (as measured by the $\mathrm{I}^{2}$ with respect to

Table 2 Characteristics of 20 studies reporting progression of cervical subluxations

\begin{tabular}{|c|c|c|c|c|c|c|c|c|}
\hline $\begin{array}{l}\text { Year of } \\
\text { publication }\end{array}$ & $\begin{array}{l}\text { First author } \\
\text { (reference) }\end{array}$ & Country & $\begin{array}{l}\text { STROBE checklist } \\
\text { (total = 22) }\end{array}$ & Sample size & $\begin{array}{l}\text { Female, number } \\
\text { (percentage) }\end{array}$ & $\begin{array}{l}\text { Mean age, } \\
\text { years }\end{array}$ & $\begin{array}{l}\text { Disease duration, } \\
\text { years }\end{array}$ & $\begin{array}{l}\text { Years of } \\
\text { follow-up }\end{array}$ \\
\hline 1971 & Isdale [22] & New Zealand & 13 & 171 & $\mathrm{~N} / \mathrm{A}$ & $\mathrm{N} / \mathrm{A}$ & 12.1 & 6.0 \\
\hline 1972 & Smith [23] & UK & 13 & 84 & $64(76 \%)$ & $\mathrm{N} / \mathrm{A}$ & N/A & 7.8 \\
\hline 1974 & Matthews [14] & UK & 11 & 54 & $\mathrm{~N} / \mathrm{A}$ & $\mathrm{N} / \mathrm{A}$ & N/A & 5.0 \\
\hline 1976 & Shaw [25] & UK & 11 & 75 & N/A & $\mathrm{N} / \mathrm{A}$ & N/A & 6.0 \\
\hline 1981 & Winfield [29] & UK & 14 & 100 & $56(56 \%)$ & 54.8 & 7.7 & 7.2 \\
\hline 1981 & Pellici [15] & USA & 14 & 106 & $88(83 \%)$ & 62.6 & 30.1 & 6.1 \\
\hline 1982 & Weissman [60] & USA & 16 & 109 & $90(83 \%)$ & 63.1 & 20.9 & 4.9 \\
\hline 1983 & Winfield [7] & UK & 17 & 100 & $57(57 \%)$ & 57.1 & 10.0 & 9.5 \\
\hline 1987 & Morizono [32] & Japan & 14 & 27 & 27 (100\%) & 56.3 & 22.4 & 5.3 \\
\hline 1989 & Rana [16] & USA & 15 & 41 & $\mathrm{~N} / \mathrm{A}$ & $\mathrm{N} / \mathrm{A}$ & N/A & 10 \\
\hline 1995 & Oda [61] & Japan & 14 & 49 & $43(88 \%)$ & 53.8 & 10.0 & 7.8 \\
\hline 1997 & Paimela [62] & Finland & 16 & 67 & 56 (84\%) & 49.7 & 7.0 & 6.5 \\
\hline 1997 & Fujiwara [63] & Japan & 13 & 79 & 66 (84\%) & N/A & N/A & 6.4 \\
\hline 1998 & Fujiwara [8] & Japan & 17 & 173 & $146(84 \%)$ & 55.6 & 12.5 & 5.9 \\
\hline 2000 & Fujiwara [42] & Japan & 15 & 161 & 134 (83\%) & 59.5 & 16.5 & 10.2 \\
\hline 2010 & Ahn [55] & Korea & 16 & 137 & 123 (90\%) & 55.1 & 7.4 & 3.0 \\
\hline 2011 & Yurube [56] & Japan & 18 & 267 & $220(82 \%)$ & 66.9 & N/A & 6.0 \\
\hline 2012 & Kaito [64] & Japan & 18 & 38 & $33(87 \%)$ & 61.0 & 14.2 & 4.4 \\
\hline 2013 & Kaito [65] & Japan & 18 & 91 & 74 (81\%) & 60.7 & 14.9 & 3.9 \\
\hline 2014 & Yurube [66] & Japan & 19 & 228 & $183(80 \%)$ & 67.0 & 19.2 & 6.0 \\
\hline
\end{tabular}

N/A, not applicable; STROBE, Strengthening the Reporting of Observational Studies in Epidemiology. 
between-study variation) was high, but we could explore trial-level differences contributing to the heterogeneity (such as year of publication) by using meta-regression, which quantifies the effect of a study characteristic (publication year) on the overall effect of heterogeneity in the rate of $\mathrm{C}$-spine subluxations. The review may be limited by variation in study quality, especially with the earlier publications having lower STROBE scores (as is often seen when comparing older with more recent studies due to different standards). Lastly, another factor to consider when interpreting the study is that cervical complications tend to develop over time. Even though our review included data from recent studies, the long-term effects of modern DMARDs (type and how we use them) on development and progression of cervical instabilities have yet to be adequately studied, and it could take years before differences in complications can be identified as C-spine complications could take years to develop or be prevented.

\section{Conclusions}

Patients with RA are still at risk for cervical spine involvement. Over the past 50 years, we have found a significant decrease in the prevalence of aAAS, possibly due to improved disease control with modern DMARDs or changing epidemiology of RA. However, aAAS remains the most common lesion with a prevalence of $27 \%$, more than twice as common as SAS or VS. The prevalence of cervical myelopathy did not change dramatically and remains at 5\% among patients with RA. The rate of progression of cervical subluxations and myelopathy did not seem to be affected significantly by DMARDs.

\section{Abbreviations \\ aAAS: anterior atlantoaxial subluxation; AAS: atlantoaxial subluxation; Cl: confidence interval; DMARD: disease-modifying anti-rheumatic drug; RA: rheumatoid arthritis; SAS: subaxial subluxation; STROBE: Strengthening the Reporting of Observational Studies in Epidemiology; VS: vertical subluxation.}

\section{Competing interests}

The authors declare that they have no competing interests.

\section{Authors' contributions}

JP conceived of the study and participated in its design and coordination, data interpretation, and the review of the manuscript. TZ carried out the data acquisition and was involved in data interpretation and manuscript preparation. Both authors read and approved the final manuscript.

\section{Acknowledgments}

The authors thank Heather Thiessen Philbrook for statistical assistance. This project was not funded.

Received: 30 January 2015 Accepted: 27 April 2015

Published online: 31 May 2015

\section{References}

1. Garrod AE. A treatise on rheumatism and rheumatoid arthritis. London: Griffin's Medical Series; 1890.

2. Conlon PW, Isdale IC, Rose BS. Rheumatoid arthritis of the cervical spine: an analysis of 333 cases. Ann Rheum Dis. 1966;25:120-6.
3. Park WM, O'Brien W. Computer-assisted analysis of radiographic neck lesions in chronic rheumatoid arthritis. Acta Radiologicaa Diagnosis. 1969;8:529-34.

4. Meikle JA, Wilkinson M. Rheumatoid involvement of the cervical spine. Ann Rheum Dis. 1971;30:154-61.

5. Lipson S. Rheumatoid arthritis in the cervical spine. Clin Orthop Relat Search. 1989;239:121-7.

6. Reiter MF, Boden SD. Inflammatory disorders of the cervical spine. Spine. 1998;23:2755-66

7. Winfield J, Young A, Williams P, Corbett M. Prospective study of the radiological changes in hands, feet, and cervical spine in adult rheumatoid disease. Ann Rheum Dis. 1983;42:613-8.

8. Fujiwara K, Fujimoto M, Owaki H, Kono J, Nakase T, Yonenobu K, et al. Cervical lesions related to systemic progression in rheumatoid arthritis. Spine. 1998;23:2052-6.

9. Hirano K, Imagama S, Oishi Y, Kanayama Y, Ito Z, Wakao N, et al. Progression of cervical instabilities in patients with rheumatoid arthritis 5.7 years after their first lower limb arthroplasty. Mod Rheumatol. 2012;22:743-9.

10. Stevens JC, Cartlidge NE, Saunders M, Appleby A, Hall M, Shaw DA. Atlanto-axial subluxations and cervical myelopathy in rheumatoid arthritis. Q J Med. 1971;159:391-408.

11. Floyd AS, Learmonth ID, Mody G, Meyers OL. Atlantoaxial instability and neurologic indicators in rheumatoid arthritis. Clin Orthop Relat Res. 1989;177-82.

12. Imagama S, Oishi $Y$, Miura $Y$, Kanayam $Y$, Ito Z, Wakao N, et al. Predictors of aggravation of cervical spine instability in rheumatoid arthritis patients: the large joint index. J Orthop Sci. 2010;15:540-6.

13. Joaquim AF, Appenzeller S. Cervical spine involvement in rheumatoid arthritis - A systematic review. Autoimmun Rev. 2014;13:1195-202.

14. Matthews JA. Atlanto-axial subluxation in rheumatoid arthritis. Ann Rheum Dis. 1974:33:526-31.

15. Pellici PM, Ranawat CS, Tsairis P, Bryan WJ. A prospective study of the progression of rheumatoid arthritis of the cervical spine. J Bone Joint Surg Am. 1981;63:342-50.

16. Rana NA. Natural history of atlanto-axial subluxation in rheumatoid arthritis Spine. 1989;14:1054-6.

17. Halla JT, Fallahi S, Hardin JG. Nonreducible rotational head tilt and lateral mass collapse. Arthritis Rheum. 1982;25:1316-24.

18. Kraus DR, Peppelman WC, Agarwal AK, DeLeeuw HW, Donalson WF. Incidence of subaxial subluxation in patients with generalized rheumatoid arthritis who have had previous occipital cervical fusions. Spine. 1991;16:S486-9.

19. Vandenbroucke JP, Elm EV, Altman DG, Gotzsche PC, Mulrow CD, Pocock SJ, et al. Strengthening the reporting of observational studies in epidemiology (STROBE): explanation and elaboration. PLoS Med. 2007:4:1628-54.

20. DerSimonian R, Laird N. Meta-analysis in clinical trials. Control Clin Trials. 1986;7:177-88.

21. Bland JH, Davis PH, London MG, Van Buskirk FW, Duarte CG. Rheumatoid arthritis of cervical spine. Arch Intern Med. 1963;112:892-8.

22. Isdale IC, Conlon PW. Atlanto-axial subluxation. Ann Rheum Dis. 1971;30:387-9.

23. Smith PH, Benn RT, Sharp J. Natural history of rheumatoid cervical luxations. Ann Rheum Dis. 1972;31:431-9.

24. Henderson DR. Vertical atlanto-axial subluxation in rheumatoid arthritis. Rheumatol Rehabil. 1975;14:31-8.

25. Shaw DA, Cartlidge NE. Cervical myelopathy in rheumatoid arthritis. Acta Neurol Belg. 1976;76:279-82.

26. Higashiyama $Y$, Matsui $N$, Inoue $S$. Atlanto-axial subluxation in rheumatoid arthritis. Rheumatism. 1978;18:246-55.

27. Chevrot A, Correas G, Pallardy G. Cervical involvement in rheumatoid arthritis. J Radio Electrol. 1978:59:545-50.

28. Jensen $\mathrm{OH}$. Atlanto-axial subluxation in rheumatoid arthritis. Ugeskr Laeger. 1979;141:2448-51.

29. Winfield J, Cooke D, Brook AS, Corbett M. A prospective study of the radiological changes in the cervical spine in early rheumatoid disease. Ann Rheum Dis. 1981;40:109-14.

30. Haaland K, Aadland HA, Haavik TK, Vallersnes FM. Atlanto-axial subluxation in rheumatoid arthritis. Scand J Rheumatol. 1984;13:319-23.

31. Redlund-Johnell I, Pettersson H. Subaxial antero-posterior dislocation of the cervical spine in rheumatoid arthritis. Scand J Rheumatol. 1985;14:355-63.

32. Morizono Y, Sakou T, Kawaida H. Upper cervical involvement in rheumatoid arthritis. Spine. 1987;12:721-5. 
33. Collins DN, Barnes CL, FitzRandolph RL. Cervical spine instability in rheumatoid patients having total hip or knee arthroplasty. Clin Orthop Relat Res. 1991;272:127-35.

34. Kauppi M, Sakaguchi M, Konttinen YT, Hamalainen M. A new method of screening for vertical atlantoaxial dislocation. J Rheumatol. 1990;17:167-72.

35. Halla JT, Hardin JG. The spectrum of atlantoaxial facet joint involvement in rheumatoid arthritis. Arthritis Rheum. 1990;33:325-9.

36. Veerapen $K$, Mangat $G$, Watt I, Dieppe $P$. The expression of rheumatoid arthritis in Malaysian and British patients: a comparative study. Br J Rheumatol. 1993:32:541-5.

37. Stiskal MA, Neuhold A, Szolar DH, Saeed M, Czerny C, Leeb B, et al. Rheumatoid arthritis of the craniocervical region by MR imaging: detection and characterization. AJR Am J Roentgenol. 1995;165:585-92.

38. Montemerani M, Venturi C, Bracco S, Coviello G, Minari C, Fioravanti A, et al. Involvement of atlanto-axial joint in rheumatoid arthritis: rare or frequent? Clin Rheumatol. 1994;13:459-64.

39. Aggarwal A, Kulshreshtha A, Chaturvedi V, Misra R. Cervical spine involvement in rheumatoid arthritis: prevalence and relationship with overall disease severity. J Assoc Physicians India. 1996;44:468-71.

40. Schramm M, Kuhr M, Wald A, Willauschub W. Prevalence, natural course and radiographic evaluation of cervical spine affection by rheumatoid arthritis. Neuro-Orthopedics. 1998;22:59-68.

41. Yoshida K, Hanyu T, Takahashi HE. Progression of rheumatoid arthritis of the cervical spine: radiographic and clinical evaluation. J Orthop Sci. 1999;4:399-406.

42. Fujiwara K, Owaki H, Fujimoto M, Yonenobu K, Ochi T. A long-term follow-up study of cervical lesions in rheumatoid arthritis. J Spinal Disord. 2000;13:519-26.

43. Neva MH, Kauppi MJ, Kautiainen H, Luukkainen R, Hannonen P, Leirisalo-Repo M, et al. Combination drug therapy retards the development of rheumatoid atlantoaxial subluxations. Arthritis Rheum. 2000;43:2397-401.

44. Riise T, Jacobsen BK, Gran JT. High mortality in patients with rheumatoid arthritis and atlantoaxial subluxation. J Rheumatol. 2001;28:2425-9.

45. Carmona L, Gonzalez-Alvaro I, Balsa A, Belmonte MA, Tena X, Sanmarti R. Rheumatoid arthritis in Spain: occurrence of extra-articular manifestations and estimates of disease severity. Ann Rheum Dis. 2003;62:897-900.

46. Neva MH, Isomaki $\mathrm{P}$, Hannonen P, Kauppi M, Krishman E. Early and extensive erosiveness in peripheral joints predicts atlatnoaxial subluxations in patients with rheumatoid arthritis. Arthritis Rheum. 2003:48:1808-13.

47. Mitsuka T, Miura T, Ueyama K, Sannohe A, Katano H, Toh S. Correlation between severity of rheumatoid arthritis and manner and extent of cervical lesion. Mod Rheumatol. 2004;14:301-5.

48. Pisitkun P, Pattarowas C, Siriwongpairat $P$, Totemchokchyakaran $K$, Nantiruj K Janwityanujit S. Reappraisal of cervical spine subluxation in Thai patients with rheumatoid arthritis. Clin Rheumatol. 2004;23:14-8.

49. Naranjo A, Carmona L, Gavrila D, Balsa A, Belmonte MA, Tena X, et al. Prevalence and associated factors of anterior atlantoaxial luxation in a nation-wide sample of rheumatoid arthritis patients. Clin Exp Rheumatol. 2004;22:427-32.

50. Zikou A, Almanos Y, Argyropoulou MI, Tsifetaki N, Tsampoulas C, Voulgari PV, et al. Radiological cervical spine involvement in patients with rheumatoid arthritis: a cross sectional study. J Rheumatol. 2005:32:801-6.

51. Vesela M, Stetkarova I, Lisy J. Prevalence of C1/C2 involvement in Czech rheumatoid arthritis patients, correlation of pain intensity, and distance of ventral subluxation. Rheumatol Int. 2005;26:12-5.

52. Neva MH, Hakkinen A, Makinen H, Hannonen P, Kauppi M, Sokka T. High prevalence of asymptomatic cervical spine subluxation in patients with rheumatoid arthritis waiting for othopaedic surgery. Ann Rheum Dis. 2006;65:884-8

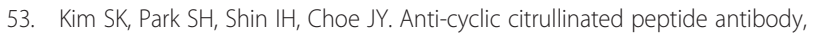
smoking, alcohol consumption, and disease duration as risk factors for axtraarticular manifestations in Korean patients with rheumatoid arthritis. J Rheumatol. 2008;35:995-1001.

54. Al-Ghamdi A, Attar SM. Extra-articular manifestations of rheumatoid arthritis: a hospital-based study. Ann Saudi Med. 2009;29:189-93.

55. Ahn JK, Hwang J, Oh JM, Lee J, Lee YS, Jeon CH, et al. Risk factors for development and progression of atlantoaxial subluxation in Korean patients with rheumatoid arthritis. Rheumatol Int. 2011;31:1363-8.

56. Yurube T, Sumi M, Nishida K, Takabatake M, Kohyama K, Matsubara T, et al. Progression of cervical spine instabilities in rheumatoid arthritis. Spine. 2011;36:647-53
57. Yurube T, Sumi M, Nishida K, Miyamoto H, Kohyama K, Matsubara T, et al. Incidence and aggravation of cervical spine instabilities in rheumatoid arthritis. Spine. 2012;37:2136-44.

58. Eser F, Garip Y, Bodur H. Extraarticular manifestations in Turkish patients with rheumatoid arthritis: impact of EAMs on the health-related quality of life in terms of disease activity, functional status, severity of pain, and social and emotional functioning. Rheumatol Int. 2012;32:1521-5.

59. Blom M, Creemers MC, Kievit W, Lemmens JA, Van Riel PL. Long-term follow-up of the cervical spine with conventional radiographs in patients with rheumatoid arthritis. Scand J Rheumatol. 2013;42:281-8.

60. Weissman BN, Aliabadi P, Weinfeld MS, Thomas WH, Sosman JL. Prognostic features of atlantoaxial subluxation in rheumatoid arthritis. Radiology. 1982;144:745-51.

61. Oda T, Fujiwara K, Yonenobu K, Zuma B, Ochi T. Natural course of cervical spine lesions in rheumatoid arthritis. Spine. 1995;20:1128-35.

62. Paimela $L$, Laasonen $L$, Kankaanpää E, Leirisalo-Repo M. Progression of cervical spine changes in patients with early rheumatoid arthritis. J Rheumatol. 1997;24:1280-4.

63. Fujiwara K, Yonenobu K, Ochi T. Natural history of upper cervical lesions in rheumatoid arthritis. J Spinal Disord. 1997;10:275-81.

64. Kaito T, Hosono N, Shima S, Ohwaki H, Takenaka S, Fujiwara H, et al. Effect of biological agents on cervical spine lesions in rheumatoid arthritis. Spine. 2012;37:1742-6.

65. Kaito T, Oshima S, Fujiwara H, Makino T, Yonenobu K. Predictors for the progression of cervical lesion in rheumatoid arthritis under the treatment of biological agents. Spine. 2013;38:2258-63.

66. Yurube T, Sumi M, Nishida K, Miyamoto H, Kohyama K, Matsubara T, et al. Accelerated development of cervical spine instabilities in rheumatoid arthritis: a prospective minimum 5-year cohort study. PLoS One. 2014;9:e88970-9.

67. Ranawat CS, O'Leary P, Pellicci P, Tsairis P, Marchisello P, Dorr L. Cervical fusion in rheumatoid arthritis. J Bone Joint Surg. 1979;61:1003-10.

68. Zoli A, Priolo F, Galossi A, Altomonte L, Di Gregorio F, Cerase A, et al. Craniocervical junction involvement in rheumatoid arthritis: a clinical and radiological study. J Rheumatol. 2000;27:1178-82

69. Kim DH, Hilibrand AS. Rheumatoid arthritis in cervical spine. J Am Acad Orthop Surg. 2005;13:463-74.

\section{Submit your next manuscript to BioMed Central and take full advantage of:}

- Convenient online submission

- Thorough peer review

- No space constraints or color figure charges

- Immediate publication on acceptance

- Inclusion in PubMed, CAS, Scopus and Google Scholar

- Research which is freely available for redistribution 